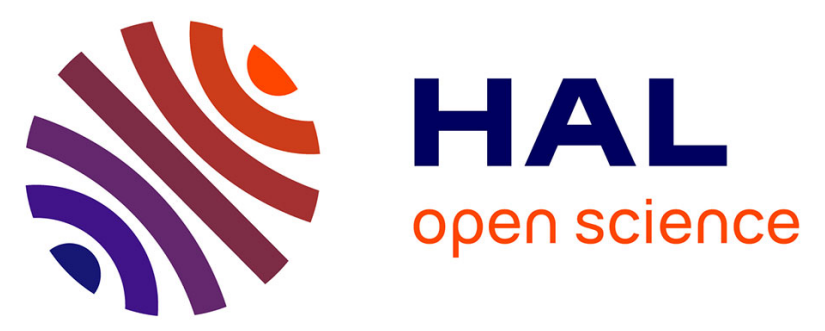

\title{
Laryngeal teflonoma identified by Fourier-transform infrared microspectroscopy after forensic autopsy: An interesting tool for foreign material identification in forensic cases
}

Sébastien Duband, Alexandre Govin, Jean-Marc Dumollard, Fabien Forest, Thierry Basset, Michel Peoc'H

\section{To cite this version:}

Sébastien Duband, Alexandre Govin, Jean-Marc Dumollard, Fabien Forest, Thierry Basset, et al.. Laryngeal teflonoma identified by Fourier-transform infrared microspectroscopy after forensic autopsy: An interesting tool for foreign material identification in forensic cases. Forensic Science International, 2012, 214 (1-3), pp.e26-e29. 10.1016/j.forsciint.2011.07.036 . hal-00656839

\section{HAL Id: hal-00656839 https://hal.science/hal-00656839}

Submitted on 5 Jan 2012

HAL is a multi-disciplinary open access archive for the deposit and dissemination of scientific research documents, whether they are published or not. The documents may come from teaching and research institutions in France or abroad, or from public or private research centers.
L'archive ouverte pluridisciplinaire HAL, est destinée au dépôt et à la diffusion de documents scientifiques de niveau recherche, publiés ou non, émanant des établissements d'enseignement et de recherche français ou étrangers, des laboratoires publics ou privés. 


\section{Elsevier Editorial System(tm) for Forensic Science International Manuscript Draft}

Manuscript Number:

Title: Laryngeal teflonoma identified by Fourier-transform infrared microspectroscopy after forensic autopsy: An interesting tool for foreign material identification in forensic cases

Article Type: Case Report

Section/Category: Forensic Osteology and Anthropology

Keywords: Fourier-transform infrared spectrometry; infrared microscopy; Teflon; teflonoma; vocal cord; asphyxia

Corresponding Author: Mr. Sébastien Duband, MD

Corresponding Author's Institution: Bellevue Hospital

First Author: Sébastien Duband, MD

Order of Authors: Sébastien Duband, MD; Alexandre Govin; Jean-Marc Dumollard, MD; Fabien Forest , MD; Thierry Basset, Pharm D; Michel Péoc'h, MD, PhD

Abstract: Forensic pathologists are sometimes confronted with microscopic foreign bodies mixed in soft tissues surrounding wounds and which are difficult to identify. This identification, however, could be primordial to investigate a crime and to determine the weapon used. A case of a fatal respiratory distress syndrome due to conjoining suicidal drug intoxication and laryngeal obstruction by a voluminous foreign body giant cell granuloma is presented. The classical histological examination showed exogenous particles in the vocal cord tumor with birefringent qualities. Their analysis with Fourier-Transform infrared (FTIR) spectrometry coupled with infrared microscope allows the determination of their chemical nature as polytetrafluoroethylene and to diagnose a teflonoma. This case report put the stress on the forensic interest of the FTIR imaging.

Suggested Reviewers: 


\section{Dear Editor,}

We would like to submit an original case to the Forensic Science International entitled « Laryngeal teflonoma identified by Fourier-transform infrared microspectroscopy after forensic autopsy: An interesting tool for foreign material identification in forensic cases».

This report deals with a rare iatrogenic injury of vocal cords which can be macroscopically confused with a malignant tumour. This lesion is due to Teflon injection and, in our case, has been identified using a Fourier-transform infrared microspectroscopy.

Being aware of the large diffusion of your journal, we hope that this short report can find a place in your excellent journal.

All authors have read and approved the final manuscript.

I remain sincerely yours

Dr S. Duband 


\title{
Laryngeal teflonoma identified by Fourier-transform infrared microspectroscopy after forensic autopsy
}

\section{An interesting tool for foreign material identification in forensic cases}

\author{
Sébastien Duband ${ }^{1,2}$, Alexandre Govin ${ }^{3}$, Jean-Marc Dumollard ${ }^{2}$, Fabien Forest ${ }^{2}$, \\ Thierry Basset ${ }^{4}$, Michel Péoc'h ${ }^{1,2}$
}

1. Forensic Medicine Department, Bellevue Hospital, University Hospital of Saint-Etienne, 42055 ST ETIENNE CEDEX 2

2. Pathology department, North Hospital, University Hospital of Saint-Etienne, 42055 ST ETIENNE CEDEX 2

3. SPIN Center, Powder and multi-compounds materials Department, Ecole Nationale Supérieure des Mines de St Etienne, 158 Cours Fauriel 42023 St Etienne Cedex 2

4. Toxicology department, North Hospital, University Hospital of Saint-Etienne, 42055 ST ETIENNE CEDEX 2

Tel : +33(0)4 77120523

Fax : +33(0)04 77120916

Corresponding author: Sébastien Duband sebastien.duband@chu-st-etienne.fr 


\section{Introduction}

Forensic pathologists are often confronted with microscopic foreign bodies mixed with biological tissues for which morphological identification is very difficult or impossible .This is the case, for example, of wounds soiled by telluric fragments or firearm injuries in which various components of missiles or intermediary targets (metals, glass, plastics...) can be found [1]. Sometimes the identification of this foreign material could lead to identifying the weapon, the instruments used to perpetrate a murder or the crime scene if the body was found on a site other than that of actual death. In many cases, scanning electron microscopy with energy-dispersive X-ray analysis (SEMEDXA) is proposed for this specialized work. This technique requires, however, a specific conditioning and a particular preparation of the samples and does not allow standard histological analysis. Nevertheless, the histological examination is essential to look for a vital reaction in contact with these exogenous elements and so consider a possible survival time after the traumatism. In these conditions, SEM-EDXA forces the practitioner to divide his samples for both analyses with a resulting risk of losing invaluable information. We present a forensic case for which foreign surgical material found in the vocal folds of a formalin-fixed larynx was identified with Fourier-transform infrared microspectroscopy without altering the histological analysis quality.

\section{Case report}

A 40 year-old man, whilst at home, called the emergency medical service after an intentional suicidal drug overdose. Upon the resuscitation team's arrival, he was in cardio-circulatory arrest and, in spite of extensive cardio-pulmonary resuscitation with mask ventilation and external electric shocks, he died after an unsuccessful orotracheal intubation. No suicide note, evidence of a fight or burglary was found by the police investigators. Empty blister packs of cyamemazine 
were discovered in the drawer of the bedside table. According to his family circle and acquaintances, he was followed medically only for depression and treated with alprazolam and cyamemazine.

\section{Autopsy findings}

The medico-legal autopsy ordered by the justice department was performed 14 hours after death. The external body examination did not bring to light traumatic cutaneous injuries in particular defensive injuries. No signs of strangulation or wrist ligature were found. The neck dissection showed a larynx that was massively blocked by partially digested food remains that were completely blocking the lumen at the level of the vocal folds. After cleaning, the laryngeal lumen was shrunk by a voluminous hardened tumefaction that had developed at the expense of the right vocal cord, being 3 centimeters high, 2 centimeters wide and $1.2 \mathrm{~cm}$ in thickness and responsible for a stenosis that was about $40 \%$ of the laryngeal section surface (Figure 1). This tumor, invading the right vestibular fold, was linked to the laryngeal wall by an acute angle that formed an arch without any appendage formation. Its surface was roughly regular with focal sub epithelial hemorrhages. The laryngeal mucosa, situated immediately under this tumefaction, was ulcerated on a triangular $1 \mathrm{~cm}^{2}$ surface. The trachea and bronchi were entirely free. The initial examination of the lungs did not show any lesion but both of them appeared congestive (Right lung weight $=518 \mathrm{~g}$, left $=418 \mathrm{~g}$ ). The other organs were macroscopically normal.

\section{Histological investigations}

The larynx was totally extracted and fixed in $10 \%$ formalin solution. Serial horizontal cut sections of this tumor until contact with the osseous plan were performed. These samples were embedded in paraffin and $5 \mu \mathrm{m}$-thick sections were realized and stained with hematoxylin- eosin- 
saffron. According to the European harmonization of medico-legal autopsy rules [2], specimens of the main organs were sampled for histology.

Histologically, the tumor was sub mucosal, well-delineated and constituted by two parts. The deepest one, directly in contact with the thyroid cartilage, contained a multitude of rounded off foreign particles (Figure 2 A). These glassy particles were agglutinated to each other, had a pearly aspect that was poorly stained and varied 5 to 20 micrometers in diameter. Some foreign body giant multinucleate cells were in their contact. The polarized filters revealed a birefringent aspect of the particles borders (Figure 2 B). This area was well bound by the second, more superficial, part of the tumor, by a surrounding collagenous fibrosis. This superficial zone was in contact with the laryngeal lumen and was made by a foreign body inflammatory granuloma with many multinucleate giant cell histiocytes containing eosinophilic, hyaline, stellate bodies that were morphologically identical to the asteroid bodies associated with sarcoid (Figure 2 C). No malignant or dysplastic cells were seen. Special stains for acid-fast bacilli and fungi were negative.

The slides of the lungs and liver of this man also showed characteristic sarcoid noncaseating granuloma composed of an aggregate of tightly clustered epithelioid cells with occasional Langhans' type giant cells surrounded with a crown of lymphocytes.

\section{Toxicological analysis}

Femoral blood, urine, gastric contents and bile samples were made during the procedure for toxicological analysis. A large screening of drugs and toxics was performed in all available samples using gas chromatography - mass spectrometry (GC-MS). Inorganic compounds were screening in blood and urine using plasma atomic emission spectrometry (ICP-AES) and flame or electrothermal atomic absorption spectrometry (FAAS, ETAAS). More selective analyses for 
several classes of therapeutic drugs or drugs of abuse were carried out in blood, urine and gastric content with various ad-hoc methods using both high-performance liquid chromatography coupled to a diode array detector (HPLC-DAD) and GC with various detection modes. A headspace technique coupled with gas chromatography - mass spectrometry technique (HS-GCMS) dedicated for volatile substances investigations was performed in blood. Blood alcohol concentration was analyzed by headspace gas chromatography with a flame ionization detector (HS/GC/FID).

Blood alcohol level was negative $(<0.1 \mathrm{~g} / \mathrm{l})$. The cardiac and femoral blood concentrations of cyamemazine were of $0.8 \mathrm{mg} / \mathrm{l}$ ruling out any redistribution phenomenon. This concentration was over the therapeutic ranges (0.03 to $0.5 \mathrm{mg} / \mathrm{l})$ indicating an overdose. Toxicological investigations of urine showed presence of cyamemazine and its metabolites.

\section{Fourier-transform infrared microspectroscopy analysis}

The tumour area of foreign bodies that was identified with optical microscope and embedded in paraffin was micro dissected. Sections of $5 \mu \mathrm{m}$ thick were performed and deposited on pastilles of $\mathrm{KBr}$ of $1 \mathrm{~cm}$ in diameter and $1 \mathrm{~mm}$ in thickness. Preparations were analyzed using a fully automated Fourier-Transform-Infrared (FTIR) imaging microscope (Hyperion 3000) coupled with Vertex 70 FTIR spectrometer, both of them produced by Brucker Optics (Marne La Vallée, France). The detector was a FPA multi-detectors (64x64) cooled by liquid nitrogen. For each sample, the FTIR microscopic analysis was operated in transmission mode. The spectral range of analysis was 3800 to $900 \mathrm{~cm}^{-1}$ with a spectral resolution of $4 \mathrm{~cm}^{-1}$ and 512 scans per spectrum. Infrared maps were built by integrating each spectrum. Images of size 200 x $200 \mu \mathrm{m}$ were obtained with spatial resolution of $3.1 \times 3.1 \mu \mathrm{m}$.

The analysis of the spectrum extracted from the position of foreign particles (crossing of red and 
green lines) led to identifying, unambiguously, foreign bodies as polytetrafluoroethylene (PTFE) particles (Figure 3 D). Indeed, the bands at 1212 and $1154 \mathrm{~cm}^{-1}$ are characteristic of asymmetric stretching vibrations and symmetric of C-F bonds, while the two sets of peaks around 2900 and $1450 \mathrm{~cm}^{-1}$ are specific in paraffin (stretching and bending of $\mathrm{C}-\mathrm{H}$ bonds). After integrating spectra in the range $1400-1000 \mathrm{~cm}^{-1}$, IR image allows one to track the spatial distribution of PTFE entities based on levels of relative absorbance intensity (figure 3 B). From this, one can acquire a map in which the absorbance intensity is proportional to thermal color changes: blue (lowest intensity) < yellow < pink (highest intensity). The same method was applied in the range $3100-2700 \mathrm{~cm}^{-1}$ in order to reveal paraffin (figure $3 \mathrm{C}$ ). The correlation between figures $3 \mathrm{~A}$ and 3B confirms the presence of bands at 1212 and $1154 \mathrm{~cm}^{-1}$ only on the foreign particles and, therefore, their chemical composition. Figure 3C, which corresponds to the distribution of paraffin on a specimen, after integrating spectrum in the range $3100-2700 \mathrm{~cm}^{-1}$, reveals a lower amount of paraffin on the foreign particles than elsewhere.

\section{Data synthesis}

Following the completion of the investigation and autopsy, the death was attributed to a respiratory distress syndrome due to conjoining cyamamezine intoxication and agonal laryngeal obstruction by both food regurgitation and inhalation phenomenon and teflonoma and was classified as suicide. The consultation of this man's medical file taught us that, 20 years earlier, he had been the victim of a motorcycle accident responsible for a laryngeal traumatism. Unfortunately, the nature of the laryngeal injuries and the surgical care were not available.

\section{Discussion}

This case report illustrates a rare laryngeal iatrogenic lesion due to surgical implantation of 
foreign material and the use of an infrared microscope coupled with FTIR spectrometer to identify the chemical nature of these foreign particles highlighting its forensic utilities and potentials. Furthermore, it allows the discussion of the pathogenesis relationship between foreign body reaction and diffuse and generalized granulomatosis.

Vocal cord paralysis may result in aspiration problems secondary to open glottic incompetence during deglutition, an ineffective cough and poor voice production. In order to correct these deficits and restore glottic competence, the paralyzed vocal cords must be nearer to the midline facilitating the functioning vocal cord to close the glottis. Brunings, in 1911, was the first to successfully treat patients with vocal paralysis by injecting paraffin into the paralyzed cord [3]. The functional results were initially good but frequent extravasation of the paraffin led to the production in surrounding tissues of a "paraffinoma". Subsequently, various substances were used including autogenous cartilage graft, bovine bone paste, silicone, tantalum powder and Teflon. The surgical use of Teflon was progressively abandoned because of important reactions to foreign bodies [4]. In fact, Teflon causes an immediate inflammatory reaction with active phagocytosis and formation of giant cells. By 2 months, the acute inflammation subsides and actively phagocytizing giant cells are seen surrounding the Teflon particles $[5,6]$. In humans, dense collagenous tissue encapsulating a granulomatous reaction is seen within 3-6 months after injection [7]. This foreign-body reaction persists and may progress, sometimes causing a stiff vocal cord and poorer voice quality that is difficult to correct surgically. Actually, abdominal fat injections are performed but with an uncertain stability of results $[8,9]$.

Bad Teflon injections (overinjection, injection that is too deeper too superficial, too close to the vocal cord margin) led to the production of a neck or laryngeal mass, so-called teflonoma, mimicking a neoplasm and exacerbation of preexisting symptoms. In our case, the laryngeal obstruction due to exuberant reaction against Teflon had participated in asphyxial syndrome by 
blocking the airway when vomiting and so inhalation phenomenon occurred after loss of conciousness due to cyamemazine intoxication.

In this particular case, a relationship could be discussed between local foreign body multinucleate cell reaction and diffuse granulomatosis like sarcoidosis as testifying hepatic and pulmonary noncaseating granuloma. If granulomas have been described at the sites neighboring the area of local Teflon injection or in regional lymph nodes, only experimental animal studies have resulted in generalized and systemic granulomas in the lungs, brain, kidneys and liver at distance of the injection point [10]. Furthermore, only one human case report of lung involvement following periurethral injection for urinary incontinence was reported in 1983 [11]. This observation was attributed to an embolization of a particle of Teflon. In our case, the hepatic and pulmonary observed granulomas did not show any foreign body within them. These visceral granulomas could support an underlying systematic granulomatosis like sarcoidosis which can also have laryngeal localization [12].

Finally, we want to highlight the forensic interests of infrared microscope coupled with FTIR spectrometer which can be used to identify the nature of foreign materials in human injured tissues prepared for standard histological examination. Previous studies have already used this technique to identify wound fragments from cutaneous sites [1]. It could be applied on paraffinembedded tissues and bring invaluable complementary information. The results can be superposed to those obtained with classical light microscopic examination such as the existence of a vital reaction to exogenous particle contact which is not possible with SEM-EDXA necessitating the samples division. This could be very interesting in order to identify intermediary targets or bullets used for a gunshot or a blunt object responsible for cutaneous wounds. 


\section{References}

[1] K.L. Maggio, V.F. Kalasinsky, M.R. Lewin-Smith, F.G. Mullick, Wound fragments from cutaneous sites of US military personnel deployed in operation Iraqi freedom: clinical aspects and pathologic characterizations, Dermatol. Surg. 34 (2008) 475-482.

[2] B. Brinkmann, Harmonisation of medico-legal autopsy rules, Int. J. Leg. Med. 113 (1999) 114.

[3] W. Brunings, Über eine neue Behandlungsmethode der Rekurrenslähmung, Verh. Dtsch. Laryngol. 18 (1911) 93-151.

[4] M.A. Varvares, W.W. Montgomery, R.E. Hillman, Teflon granuloma of the larynx: etiology, pathophysiology and management, Ann. Otol. Rhinol. Laryngol. 105 (1995) 511-5.

[5] F. Kirchner, P. Toledo, D. Svoboda, Studies of the larynx after Teflon injection, Arch. Otolaryngol. 83 (1966) 350-4.

[6] J.M. Toomy, B.S. Brown, The histological response to intracordal injection of Teflon paste. Laryngoscope 77 (1967) 110-20.

[7] H.H. Dedo, B. Carlsoo, Histologic evaluation of Teflon granulomas of human vocal cords: a light and electron microscopic study, Acta Otolaryngol. 93 (1982) 475-84.

[8] G.Y. Shaw, M.A. Szewczyk, J. Searle, J. Woodroof, Autologous fat injection into the vocal folds: technical considerations and long term follow up, Laryngoscope 107 (1997) 177-86.

[9] M.L. Shindo, L.S. Zaretsky, D.H. Rice, Autologous fat injection for unilateral vocal fold paralysis, Ann. Otol. Rhinol. Laryngol. 105 (1996) 602-6.

[10] A.A. Malizia, H.M. Reiman, R.P. Myers, J.R. Sandle, S.S. Barham, R.C. Benson, Migration and granulomatous reaction after periurethral injection of polytef (Teflon), JAMA 251 (1984) $3277-81$.

[11] R.E. Mittleman, J.V. Marraccini, Pulmonary Teflon granulomas following periurethral 
Teflon injection for urinary incontinence, Arch. Pathol. Lab. Med. 107 (1983) 611-12.

[12] R.B. McLaughlin, J.R. Spiegel, J. Selber, D.B. Gotsdiner, R.T. Sataloff, Laryngeal sarcoidosis presenting as an isolated submucosal vocal fold mass, Journal of Voice 13 (1999) $240-5$. 


\section{Figures:}

Figure 1: Anaglyph (3D photograph) showing a voluminous hardened tumor of the right vocal cord that must be observed with red/cyan glasses.

Figure 2: Black and white histological aspect of the whole teflonoma after reconstruction from several microscopic fields (magnification $\mathrm{x} 25$ ). L indicates the laryngeal lumen, $\mathrm{F}$, the fibrosis surrounding the area of foreign bodies and C, a part of arytenoid cartilage (inset A, HematoxylinEosin-Saffron stain, magnification x200). Insert B shows the polarized observation of the same area revealing the birefringent qualities of foreign material (magnification x200). The left colored microphotography focuses on the giant cell area (C, Hematoxylin-Eosin-Saffron stain, magnification $\mathrm{x} 200)$.

Figure 3: A. Microphotography of the surface of the cut after embedding (magnification x200). B. Infrared image in transmission mode after integrating spectrum in the range $1400-1000 \mathrm{~cm}^{-1}$ to reveal PTFE particles, C. Infrared image in transmission mode after integrating spectrum in the range $3100-2700 \mathrm{~cm}^{-1}$ to reveal paraffin, D. Representative infrared spectrum extracted from the maps (crossing of red and green lines) that shows the two main identified compounds of the samples: paraffin and Teflon. 
Click here to download high resolution image

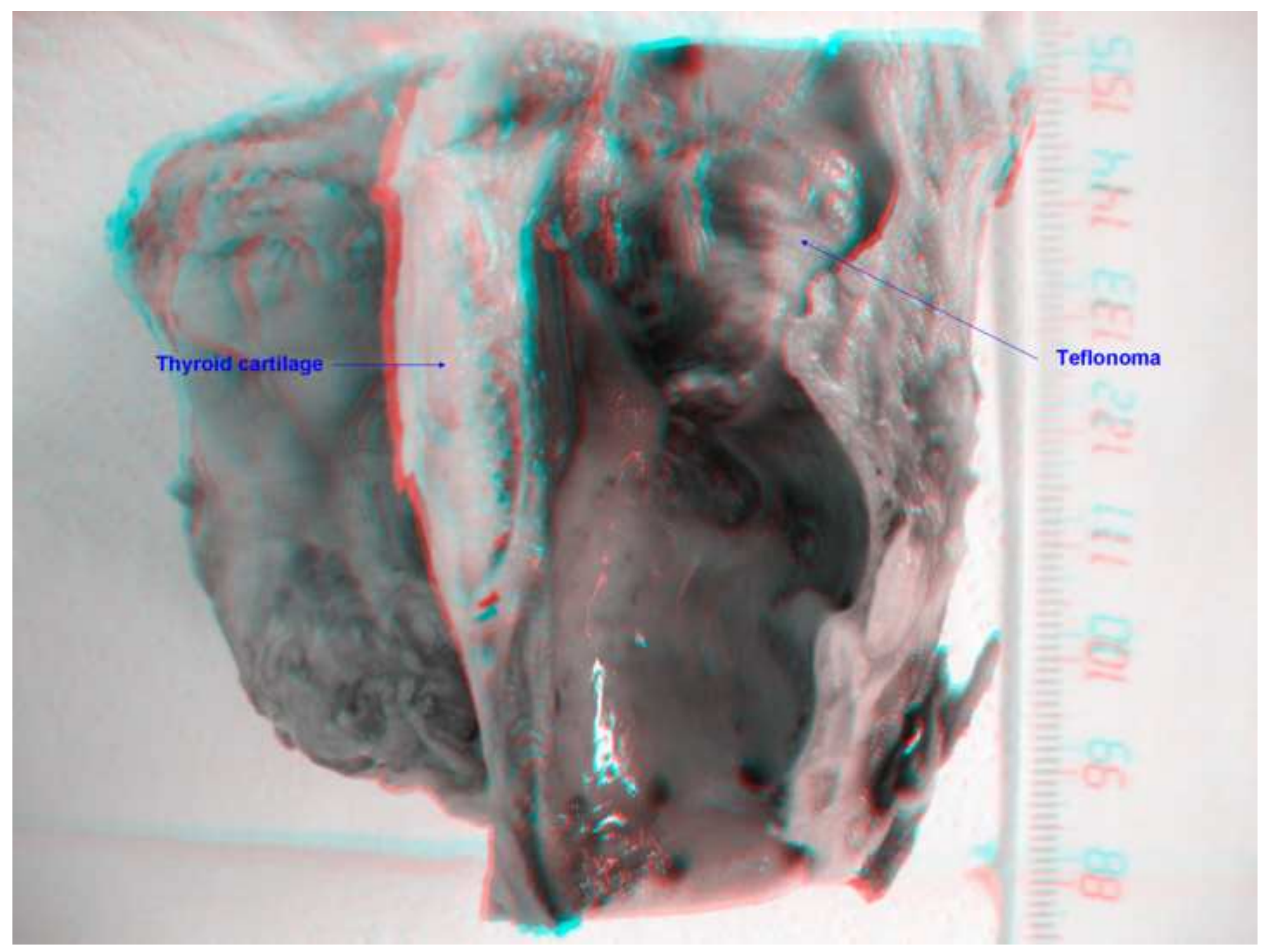


Click here to download high resolution image
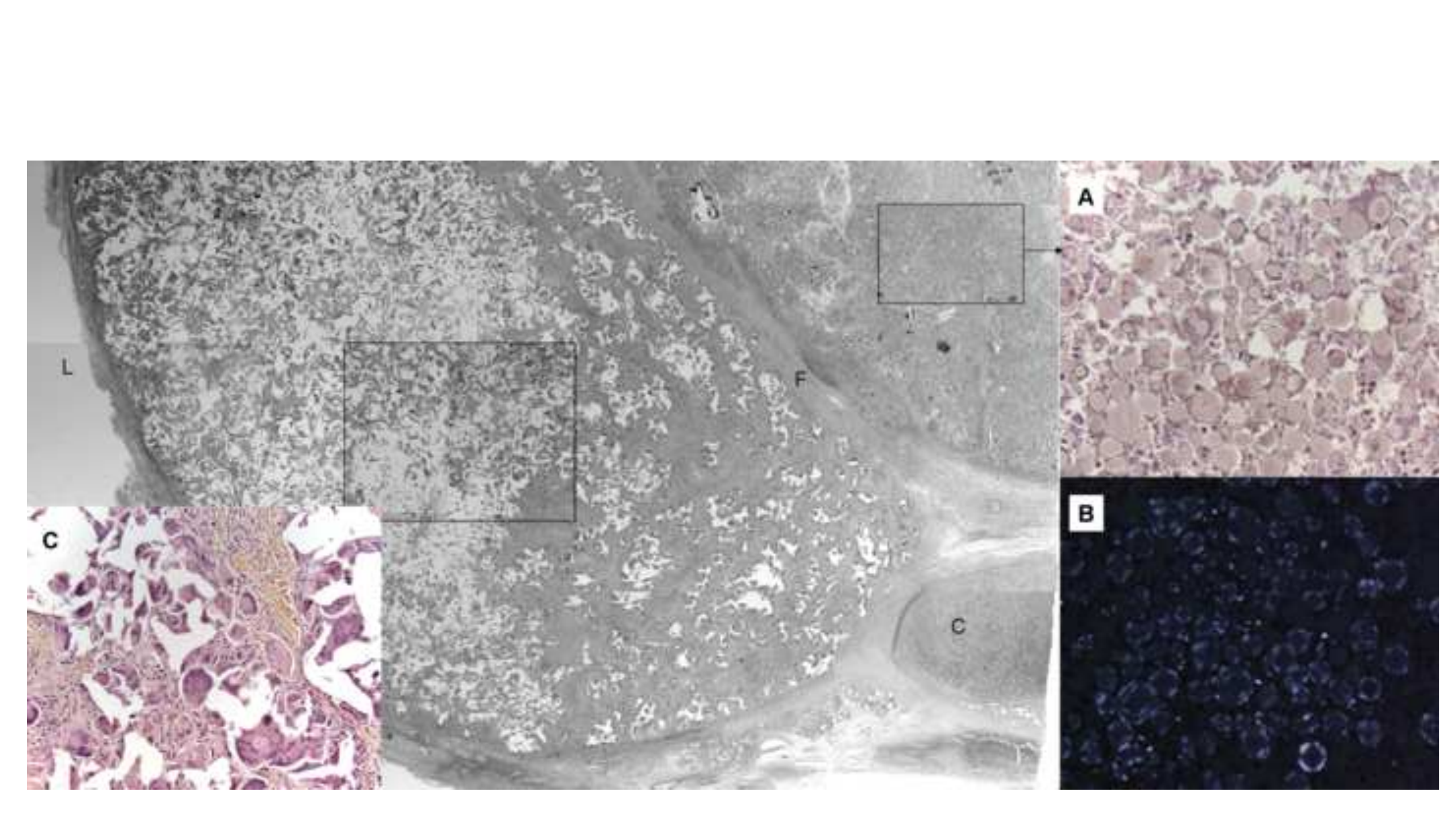

.
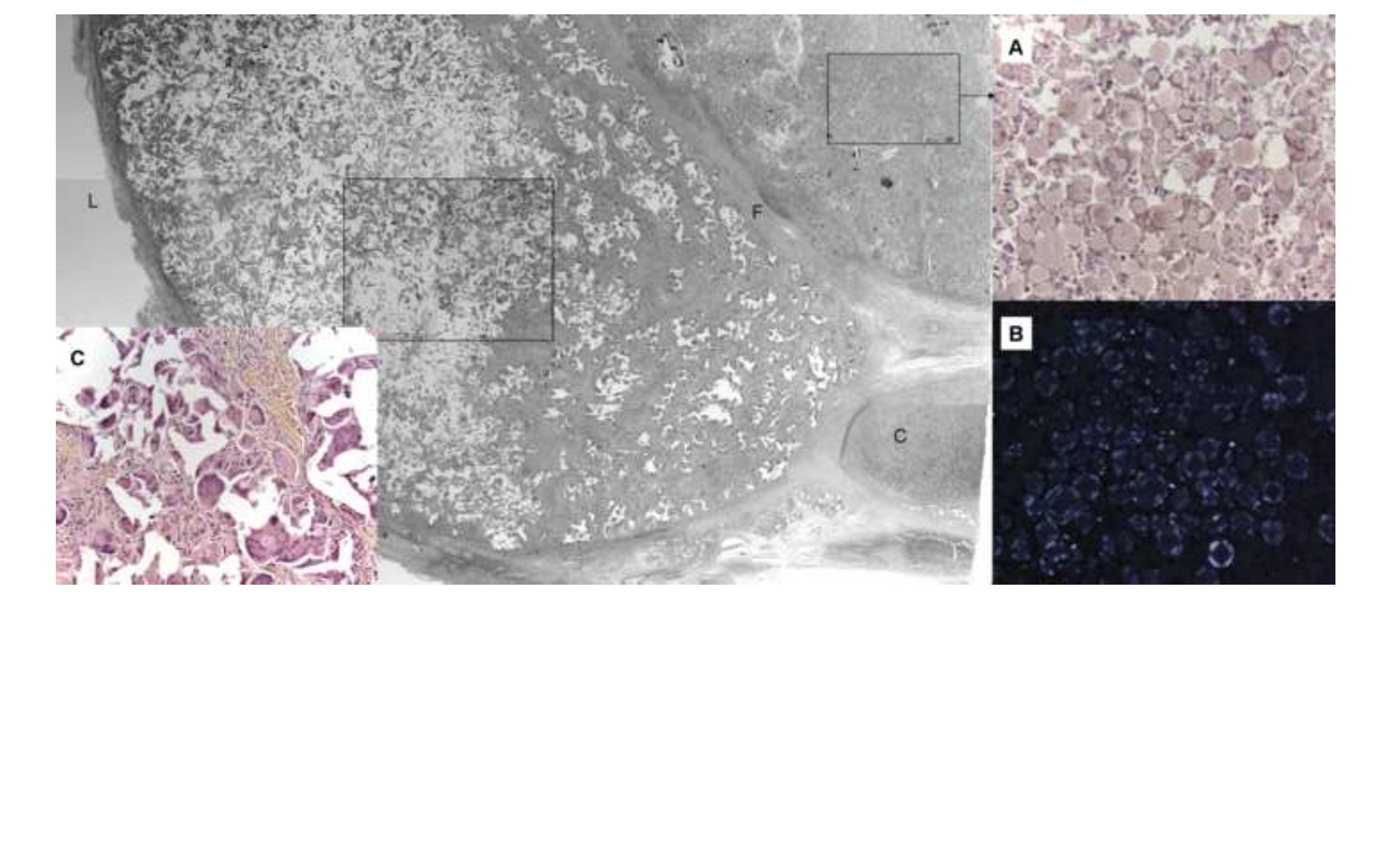
Click here to download high resolution image
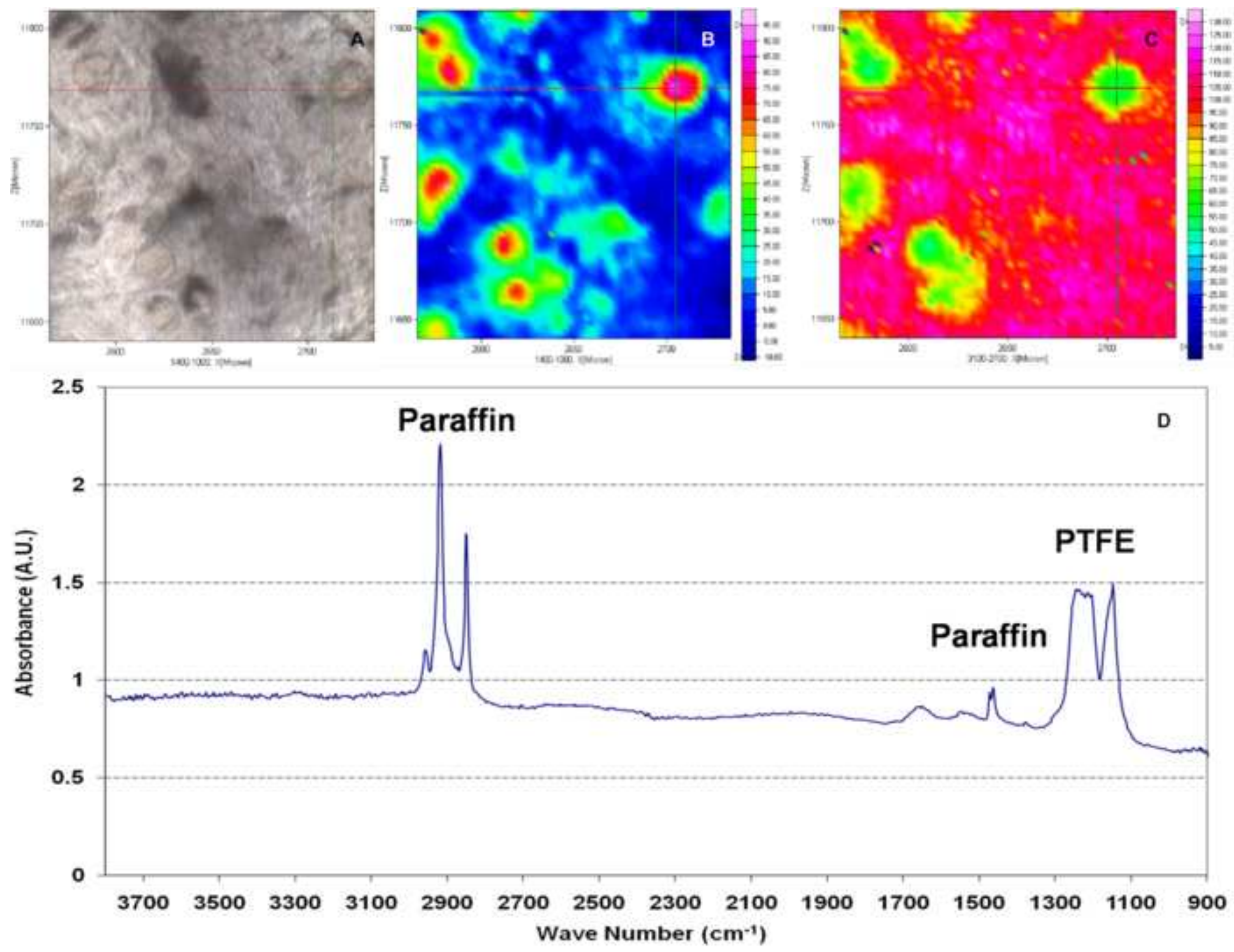

\section{Paraffin}

\section{PTFE}

Wave Number $\left(\mathrm{cm}^{-1}\right)$ 